\title{
Activated carbon produced from waste coffee grounds for an effective removal of Bisphenol-A in aqueous medium
}

Andreia Cristina Fonseca Alves ${ }^{* 1}$; Romario Victor Pacheco Antero ${ }^{2}$; Sergio Botelho de Oliveira ${ }^{3}$; Satu Anneli Ojala ${ }^{4}$; Paulo Sérgio Scalize ${ }^{1}$

${ }^{a}$ School of Civil and Environmental Engineering, Federal University of Goiás, Av. Universitária, $\mathrm{n}^{\circ} .1488$, Setor Universitário, CEP: 74605-220, Goiânia/GO - Brazil.

bInstitute of Chemistry, University of Brasília, Campus Universitário Darcy Ribeiro, P.O. Box 4478, CEP 70904-970, Brasília, DF, Brazil.

${ }^{c}$ Federal Institute of Goiás, Rua 75, nº6. Centro. CEP: 74055-110. Goiânia/GO - Brazil.

${ }^{\mathrm{d}}$ Environmental and Chemical Engineering, Faculty of Technology, University of Oulu, P.O. Box 4300, FI-90014 University of Oulu, Finland.

\begin{abstract}
Bisphenol-A is widely used chemical in industry and unfortunately often detected in natural waters. Considered as an emerging pollutant, bisphenol-A represents an environmental problem due to its endocrine disrupting behavior. The production of Activated Carbon from alternative precursors has shown to be attractive in the removal of emerging pollutants from the water. activated carbon was produced from waste coffee by physical and chemical activation and applied in the removal of bisphenol-A. The samples were characterized by elemental analysis, scanning electron microscopy, X-ray diffraction, Fourier transform infrared spectroscopy and analysis of textural properties. Bisphenol-A adsorption experiments showed that the chemically activated carbon was more efficient due to its high specific surface area $\left(1039 \mathrm{~m}^{2} / \mathrm{g}\right)$ compared to the physically activated carbon $\left(4.0 \mathrm{~m}^{2} / \mathrm{g}\right)$. The bisphenol-A adsorption data followed the pseudo second order model and Langmuir isotherm, that indicated a maximum adsorption capacity of $123.22 \mathrm{mg} / \mathrm{g}$ for chemically activated carbon. The results demonstrated a potential use of the coffee grounds as a sustainable raw material for the production of chemically activated carbon that could be used in water treatment.
\end{abstract}

\section{Keywords}

Adsorption; Bisphenol-A; Emerging pollutant; Microporous material; Residue; Treatment water

*Corresponding author. Tel: +55 (62) 98250-5067.

E-mail address: andreiacristinacfa@gmail.com (Andreia C. F. Alves) 


\section{Introduction}

Bisphenol-A (BPA) is an organic chemical used in the production of polymers, polycarbonates and epoxy resins (WHO and FAO 2010). BPA is also known as an emerging pollutant. BPA is an endocrine disrupting chemical and it is being detected in natural waters destined for public water supply (Moreira et al. 2011; Sodré et al. 2007). Conventional water treatment plants are somewhat inefficient to removal of emerging compounds from water (Gwenzi et al. 2017). In this context, remediation techniques are essential to control of BPA contamination in waters.

In the case of BPA removal from water, different methods have been used. For instance, photocatalytic degradation is able to achieve BPA removal of $91 \%$ for $20 \mathrm{mg} / \mathrm{L}$ of BPA after $3.5 \mathrm{~h}$ of treatment (Xia et al. 2016). Membrane processes also achieve high capacity of removal (93\%) of BPA from contaminated water (Nasseri et al. 2018). Another removal method is the adsorption using activated carbon (AC), which presents satisfactory results, as in the study of Zbair et al. (2017) which presented until 94,9\% removal of BPA using activated carbon from argan nutshell.

Activated carbon shows characteristics such as surface area, surface functional groups and chemical and textural surface properties, which have an important role in the adsorption processes. In addition, during the production process of the $\mathrm{AC}$, these characteristics can be improved to gain greater efficiency for adsorption. The production of AC can occur by chemical or physical activation and from several types of raw material.

In physical activation, the precursor is initially carbonized at temperatures above $500^{\circ} \mathrm{C}$ and then activated at high temperatures $\left(700-900^{\circ} \mathrm{C}\right)$ and using $\mathrm{CO}_{2}$ or water vapor as activating agent. In chemical activation, the precursor is treated with chemicals such as $\mathrm{ZnCl}_{2}, \mathrm{KOH}$ and $\mathrm{H}_{3} \mathrm{PO}_{4}$, which are the most commonly used industrially. Then the precursor is activated at temperatures ranging from $450-600{ }^{\circ} \mathrm{C}$ (Marsh and Rodriguez-reinoso 2006).

Different organic raw materials are used in AC production, whose nature may be either animal or vegetal. Amongst these raw materials, waste of industrial coffee production is noteworthy, since literature reports promising results concerning its adsorbing proprieties. An earlier study reported the application of AC from three different precursor materials, waste coffee grounds, melon seeds and orange peels for the adsorption of organic micropollutants, o-nitrophenol and p-nitrotoluene. The adsorption of the pollutants was in the range of 70\% to $90 \%$, and the AC of coffee grounds showed a removal around to $90 \%$ (Djilani et al. 2012). Many studies have evidenced the possibility to use AC in BPA removal from water. However, none of these reports made use of AC from coffee grounds, which implies the need for further studies in this subject. Coffee grounds is a residue that is easily available since coffee is appreciated and consumed worldwide. In addition, the production of AC from waste itself is attractive, because it makes use of materials already available without need of its extraction contributing in the reduction of the exploration of the natural resources such as mineral rocks and wood, for example, making the whole process more sustainable.

Emphasizing the search for alternative processes, the objective of this study was the production of activated carbon of high surface area using waste coffee grounds as precursor, which was collected after preparation of the coffee beverage. Water and $\mathrm{ZnCl}_{2}$ were used as the activating agent. The applicability of the prepared materials in the adsorption of BPA in aqueous medium were evaluated. 


\section{Experimental}

\section{Materials}

The coffee grounds was obtained after preparation of the coffee beverage. The Bisphenol-A (BPA) was purchased from Sigma Aldrich ${ }^{\circledR}$ ( $97 \%$ purity). The stock solution was prepared by dissolving $0.1 \mathrm{~g}$ of BPA in $1000 \mathrm{~mL}$ of ultrapure water to prepare a $100 \mathrm{mg} / \mathrm{L}$ solution. The other chemical reagents used $(\mathrm{HCl}$, $\mathrm{NaCl}, \mathrm{NaOH}$, and $\mathrm{ZnCl}_{2}$ ) were of analytical grade.

\section{Preparation of activated carbons}

The raw material was firstly washed with $\mathrm{NaOH}(0.1 \mathrm{~mol} / \mathrm{L})$ to remove impurities and water-soluble substances. Afterward, the material was washed with ultrapure water at $80{ }^{\circ} \mathrm{C}$ and washed with ultrapure water at room temperature $\left(26^{\circ} \mathrm{C}\right)$ until the $\mathrm{pH}$ of the rinse water was close to 7 . In the roasting process, the coffee beans are subjected to a temperature ranging from $180^{\circ} \mathrm{C}$ to $240{ }^{\circ} \mathrm{C}$. The coffee grounds are the residue generated after the preparation of the coffee beverage. Soon this residue refers to coffee beans that have been roasted. For this reason the carbonization was not performed because the roasting process was considered a pre-carbonization. The washed material was placed in a reactor and activated for $2 \mathrm{~h}$ in a furnace $\left(500{ }^{\circ} \mathrm{C}\right.$ at $\left.10^{\circ} \mathrm{C} / \mathrm{min}\right)$ under a continuous nitrogen flow of $50 \mathrm{~mL} / \mathrm{min}$ saturated with water vapor. Afterwards, the activated carbon was sieved in ASTM (Mesh) sieves with different sizes and the material of diameter larger than 100 mesh $(0.149 \mathrm{~nm})$ was selected for further experiments. Activated carbon prepared by physical activation with water vapor was called as $\mathrm{CAH}$.

In chemical activation the raw material was impregnated with $\mathrm{ZnCl}_{2}$, which was chosen as activating agent since it is quite effective for the development of micropores and mesopores. Besides that, zinc chloride is neutral and non-toxic salt and one most commonly used industrially (Marsh and Rodriguez-reinoso 2006). The impregnation ratio was 1:2 (activating agent/coffee grounds). For this, $10 \mathrm{~g}$ of $\mathrm{ZnCl}_{2}$ was dissolved in $60 \mathrm{~mL}$ of ultrapure water and then placed in contact with $20 \mathrm{~g}$ of coffee grounds. Impregnation was carried out at $85{ }^{\circ} \mathrm{C}$ during $7 \mathrm{~h}$ in order to facilitate the access of activating agent to the interior of the precursor, and then the temperature of the mixture was increased to $105^{\circ} \mathrm{C}$, remaining until the complete dryness for about $24 \mathrm{~h}$. The impregnated raw material was then placed in a stainless steel reactor, which was accommodated in a vertical oven at a temperature of $500{ }^{\circ} \mathrm{C}$ for $2 \mathrm{~h}$ under continuous flow of nitrogen (100 $\mathrm{mL} / \mathrm{min}$ ). A heating rate of $10{ }^{\circ} \mathrm{C} / \mathrm{min}$ was used during the carbonization. The activated carbon received was then washed with $\mathrm{HCl}$ solution $(0.1 \mathrm{~mol} / \mathrm{L})$ for pore clearing and ultrapure water until the $\mathrm{pH}$ close to 7 and then dried at $105^{\circ} \mathrm{C}$ for $24 \mathrm{~h}$. Finally, the activated carbon was sieved to get the material of diameter larger than 100 mesh $(0.149 \mathrm{~nm})$. Activated carbon prepared by chemical activation with $\mathrm{ZnCl}_{2}$ was called as CAZ.

\section{Characterization of activated carbons}

Thermogravimetric analysis (TGA) aimed to identify the principal temperature levels at which the coffee grounds reacts under an inert atmosphere. This analysis was carried out with thermal analyzer model DTG 
$60 / 60 \mathrm{H}$ (Shimadzu $\left.{ }^{\circledR}\right)$ under a nitrogen flow of $100 \mathrm{~mL} / \mathrm{min}$. The temperature range was from room temperature to $1000^{\circ} \mathrm{C}$ with a heating rate of $10^{\circ} \mathrm{C} / \mathrm{min}$.

The yield of the activated carbons was determined from Equation 1, to calculate the mass of activated carbons selected in the 100-mesh sieve.

Yield $_{A C}(\%)=\left(M_{A C} / M_{P}\right) \times 10$

where $M c$ is the mass of activated carbon ( $\mathrm{g})$ and $M p$ is the mass of precursor $(\mathrm{g})$.

The scanning range used was 400 to $4000 \mathrm{~cm}^{-1}$ with resolution of $4 \mathrm{~cm}^{-1}$ and 32 scans. Samples were diluted in $\mathrm{KBr}(1 \%$ by weight) to form the analysis disc. The elemental contents CHNSO of raw material and activated carbons were determined by using an organic elemental analyzer model FLASH 200 (Thermo Scientific $\left({ }^{\circledR}\right)$. The morphological characteristics of raw material and activated carbons were analyzed by Scanning electron microscopy (SEM) using an electronic scanning electron microscope model JSM 7100F (FEG) (JEOL®).

The crystalline structure of activated carbons was analyzed by X-ray diffraction (XRD) analysis using an X-ray diffractometer model DRX-6000 (Shimadzu®). The samples were subjected to K $\alpha$ radiation of $\mathrm{Cu}$ $(\lambda=1.5406 \AA)$, current of $30 \mathrm{~mA}$ and voltage of $45 \mathrm{kV}$ at room temperature. The scan speed used was $2 \%$ min and angular variation of $10^{\circ}-80^{\circ}$ in a band of $2 \theta$. The functional surface groups of the activated carbons were determined by Fourier Transform Infrared Spectroscopy (FTIR) using a spectrometer model Spectrum 400 (Perkin Elmer®).

The textural properties were analyzed by $\mathrm{N}_{2}$ adsorption-desorption isotherms $\left(-196{ }^{\circ} \mathrm{C}\right)$ using ASAP 2020 Plus (Micromeritics ${ }^{\circledR}$ ) instrument. The surface area was determined using the BET method (Brunauer et al. 1938). The total porous volume was obtained from the desorption isotherm from the desorbed $\mathrm{N}_{2}$ volume at the relative pressure of 0.95 , and the mean diameter and pore distribution were determined by the $\mathrm{BJH}$ method (Barrett et al. 1951).

The point of zero charge ( $\mathrm{pH}_{\mathrm{PZC}}$ ) was determined using the 11 points experiment (Park and Regalbuto 1995). The activated carbon (50 mg) was mixed with $20 \mathrm{~mL}$ of $\mathrm{NaCl}$. The starting $\mathrm{pH}$ solutions $(1,2,3,4,5,6,8,9,10,11$ and 12$)$ was adjusted using $\mathrm{HCl}(0.1 \mathrm{~mol} / \mathrm{L})$ and $\mathrm{NaOH}(0.1 \mathrm{~mol} / \mathrm{L})$. After 24 hours of shaking, the final $\mathrm{pH}$ was measured.

\section{BPA adsorption studies}

A preliminary test was carried out to evaluate the adsorption efficiency of raw material and the activated carbons (CAZ and CAH) in BPA removal. In each experiment, $10 \mathrm{mg}$ of adsorbent was added to $10 \mathrm{~mL}$ of BPA solution $(30 \mathrm{mg} / \mathrm{L})$ in $25 \mathrm{~mL}$ flasks. The flasks were kept under shaking for $24 \mathrm{~h}$ in an orbital shaker model SI-300R (Lab Companion $\left.{ }^{\circledR}\right)$, working at $180 \mathrm{rpm}$, room temperature $\left(26^{\circ} \mathrm{C}\right.$ ) and normal $\mathrm{pH}$ of the solution $(5,65)$. The adsorbent was separated from the solution by filtration with a quantitative syringe filter. The residual BPA concentration was analyzed using a UV/Vis spectrophotometer model M51 (Bel Engineering ${ }^{\circledR}$ ), at a wavelength of $283 \mathrm{~nm}$. The amount of adsorbed BPA was determined by Equation 2. 
$q_{e}=\frac{\left(C_{0}-C_{e}\right) V}{m}$

where $q_{e}$ is the adsorption capacity $(\mathrm{mg} / \mathrm{g}) ; C_{o}$ is the initial concentration of adsorbate $(\mathrm{mg} / \mathrm{L}) ; C_{e}$ is the concentration of adsorbate at equilibrium $(\mathrm{mg} / \mathrm{L}) ; V$ is the volume of the solution $(\mathrm{L}) ; m$ is the mass of the adsorbent (mg). The Equation 3 was used to calculate the BPA removal efficiency.

Removal of $B P A(\%)=\left(\frac{C_{o}-C}{C o}\right) \times 100$

where $C_{o}$ is the initial concentration of BPA $(\mathrm{mg} / \mathrm{L})$ at time zero and $C$ is the concentration remaining of BPA (mg/L) after the adsorption test.

The influence initial $\mathrm{pH}$ in the adsorption capacity of the activated carbons was evaluated for $\mathrm{pH}$ values of 2.0, 4.0, 6.0, 8.0 and 10.0, which were adjusted using $\mathrm{HCl}(0.1 \mathrm{~mol} / \mathrm{L})$ or $\mathrm{NaOH}(0.1 \mathrm{~mol} / \mathrm{L})$. In each experiment, $10 \mathrm{mg}$ of adsorbent was added to $10 \mathrm{~mL}$ of solution of BPA (30 mg/L) in $25 \mathrm{~mL}$ flasks, which were kept under stirring for $24 \mathrm{~h}$ working at $180 \mathrm{rpm}$ at room temperature $\left(26^{\circ} \mathrm{C}\right)$. The residual BPA concentration was measured after the test.

\section{Adsorption isotherm and kinetics models}

The adsorption kinetics was determined by analyzing the BPA removal from an aqueous solution at different time intervals, between $15 \mathrm{~min}$ and $24 \mathrm{~h}$. The adsorption kinetics studies were performed for three different concentrations of BPA, 5, 20 and $30 \mathrm{mg} / \mathrm{L}$. In each experiment, $10 \mathrm{mg}$ of adsorbent was added to $50 \mathrm{~mL}$ of BPA solution in $125 \mathrm{~mL}$ flasks, which were kept under stirring at $180 \mathrm{rpm}$ at room temperature $\left(26{ }^{\circ} \mathrm{C}\right)$. The fit of the experimental data was performed using kinetic models of pseudo-first-order and pseudo-second-order. The pseudo-first-order model (Lagergren 1898) can be expressed by Equation 4.

$q_{t}=q_{e}\left(1-e^{-k_{1} t}\right)$

where $k_{l}$ is the constant of the adsorption rate (1/min); $t$ is the time; qe and $q t$ are the adsorbed BPA amounts at equilibrium and at time $t$ respectively $(\mathrm{mg} / \mathrm{g})$. The pseudo-second-order model (Blanchard et al. 1984; Ho and McKay 1998) can be expressed by Equation 5.

$q_{t}=\frac{q_{e^{2}} k_{2} t}{\left(q_{e} k_{2} t+1\right)}$

where $k_{2}$ is the constant of the adsorption rate (g/mg.min).

The nature of the BPA adsorption process was determined using the Langmuir and Freundlich isotherm models. To obtain the experimental data, $10 \mathrm{mg}$ of adsorbent was added in $50 \mathrm{~mL}$ of BPA solution at the concentrations of 5,10,20,30,40,50, 60 and $70 \mathrm{mg} / \mathrm{L}$. The mixtures were shaken (180 rpm) at room 
temperature $\left(26^{\circ} \mathrm{C}\right)$. The residual BPA concentration was analyzed after $24 \mathrm{~h}$ of the experiment. The Langmuir model (Langmuir 1916) can be expressed by Equation 6.

$q_{e}=\frac{q_{\operatorname{má} k_{L} C_{e}}}{1+k_{L} C_{e}}$

where $C_{e}$ is the concentration of adsorbate at equilibrium $(\mathrm{mg} / \mathrm{L}) ; q_{\max }$ is the maximum adsorption capacity of the adsorbent $(\mathrm{mg} / \mathrm{g}) ; K_{L}$ is an interaction constant between the adsorbate and the adsorbent $(\mathrm{L} / \mathrm{mg})$.

The Freundlich model (Freundlich 1906) can be expressed by Equation 7:

$q_{e}=k_{F} C_{e}^{1 / n}$

where $K_{F}(\mathrm{mg} / \mathrm{g}) /(\mathrm{mg} / \mathrm{L})^{1 / \mathrm{n}}$ and $n$ are the Freundlich constants related to adsorption capacity and intensity respectively. The parameter $n$ indicates whether the isotherm is favorable or unfavorable, being favorable when it has values in the range of 1 to 10 . The higher the value of $n$, the stronger the interaction between adsorbate and adsorbent. The quality of the adjustments was evaluated through the correlation coefficient $\mathrm{R}^{2}$, and statistical parameter Residual Sum of Squares (RSS).

\section{Results and discussion}

\section{Characterization of activated carbons}

Thermogravimetric Analysis

The thermogravimetric analysis shows the thermal behavior of the waste coffee grounds in the range of $24{ }^{\circ} \mathrm{C}$ to $1000{ }^{\circ} \mathrm{C}$. Fig. 1 shows the relative mass loss (TG) and its first derivative (DTG) curve.

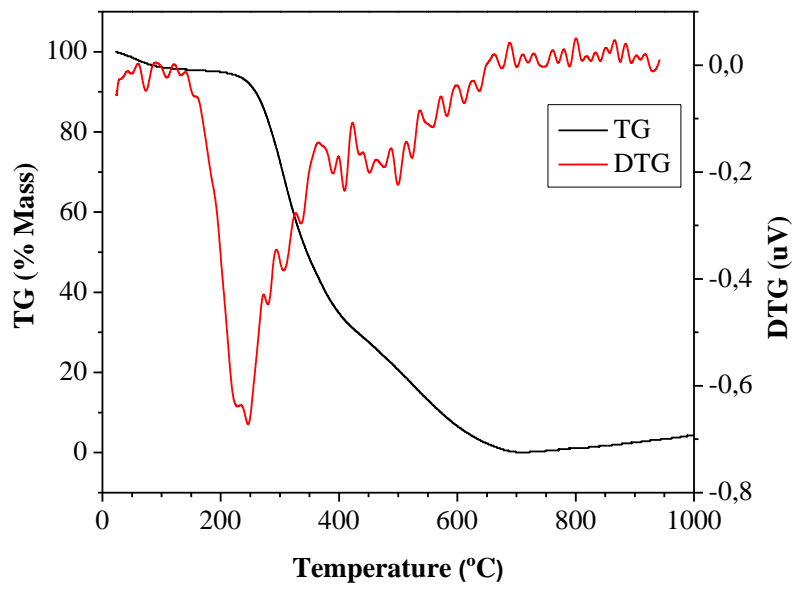

Fig. 1 Thermogravimetric analysis of waste coffee grounds under $\mathrm{N}_{2}$ flow 
The mass loss observed at a temperature lower than $150{ }^{\circ} \mathrm{C}$ can be attributed to the loss of water occluded inside of the pores or adsorbed on the coffee grounds (Singh et al. 2017). After $200{ }^{\circ} \mathrm{C}$ the mass loss is related to the degradation of coffee grounds components such as hemicellulose, cellulose and some lignin fraction. Between 200 and $300{ }^{\circ} \mathrm{C}$ the degradation of the hemicellulose occurs, followed by degradation of the cellulose between 300 and $400{ }^{\circ} \mathrm{C}$ (Yang et al. 2007). Lignin degradation occurs at higher temperatures, above $400{ }^{\circ} \mathrm{C}$ (Essabir et al. 2018). The stabilization of the mass loss of coffee grounds was observed from $600{ }^{\circ} \mathrm{C}$. Based on this result the use of a milder temperature $\left(500^{\circ} \mathrm{C}\right)$ was selected for the carbonization.

\section{Yield analysis of activated carbons}

The physical activation process using water vapor showed a yield of around $20 \%$ while for chemical activation with $\mathrm{ZnCl}_{2}$ the yield was $40 \%$. Aznar (2011) evaluated the yield of activated carbon produced from coffee grounds from the two activation methods and obtained yields varying from 12 to $18 \%$ in physical activation, while in chemical activation the yield was 35 to $50 \%$. The physical activation process occurs in two different stages (carbonization and activation), which are realized at high temperatures and consequently the yield of production is low (Marsh and Rodriguez-reinoso 2006).

In chemical activation the activating agent causes physical and chemical changes in the precursor material, which modifies the thermal degradation process. Because of these modifications, the following activation process requires lower temperatures, resulting in higher yield of production compared to physical activation. Another factor, which results in a higher yield in the chemical activation, is the decrease of the formation of tar compounds. During the carbonization step, chemical activating agent prevents the formation of these compounds, which would be released in the form of volatile compounds (RodríguezReinoso and Molina-Sabio 1992).

\section{Elemental analysis}

Table 1 presents values for the elemental composition of the raw material, CAZ and CAH, showing the carbon, hydrogen, nitrogen and oxygen contents. For comparison, the analysis was also performed for the commercial activated carbon (CAC).

Table 1 Elemental analysis of the raw material, CAZ, CAH and CAC

\begin{tabular}{lllll}
\hline Samples & $\mathrm{C}(\%)$ & $\mathrm{H}(\%)$ & $\mathrm{N}(\%)$ & $\mathrm{O} *(\%)$ \\
\hline raw material & 53.9 & 1.7 & 7.9 & 36.5 \\
CAZ & 90.2 & 2.3 & 2.5 & 5.0 \\
CAH & 80.2 & 3.1 & 3.1 & 13.6 \\
CAC & 85.2 & 1.2 & 0.0 & 13.6 \\
*Determined by difference to close the mass balance.
\end{tabular}

It is observed that an increase of the carbon content of the material occurred after the activation process. The carbon content in the samples CAZ and CAH were close to the content presented by the commercial activated carbon. The CAZ sample presented the highest increase in carbon content (90.2\%), while the 
CAH sample showed $80.2 \%$ carbon in its structure. The increase in carbon content occurs due to the release of volatile compounds and heteroatoms during the activation process. Furthermore, the high temperatures employed in this process cause the breaking of less stable chemical bonds of the precursor material. Consequently, the structural network of the material is reorganized into graphene rings increasing the carbonaceous content (Nowicki 2016).

After the activation, nitrogen and oxygen contents were decreased in the CAZ and CAH samples compared to the raw material. The decrease occurs due to the decomposition of the organic matter present in the waste coffee grounds, releasing volatile compounds, which contain nitrogen and oxygen. The decrease of the oxygen content is also related to the dehydration reactions that occur in the raw material due to the action of the activating agents (Ozdemir et al. 2014; Prauchner et al. 2016). This fact justifies the CAZ sample having a higher decrease in oxygen content (31.5 percentage points) compared to the CAH sample, that was produced by physical activation having 22.9 percentage points less oxygen than the raw material.

The hydrogen is also eliminated in the form of volatile compounds during the activation process. However, in the CAZ and CAH samples, an increase in the hydrogen content is observed when compared to the raw material $(1.7 \%)$. During the activation process, the hydrogen can be bound to the structure of the activated carbon, causing an increase in the hydrogen content (Singh et al. 2017).

\section{Scanning Electron Microscopy}

The SEM images show that the raw material (Fig. 2a) had a relatively smooth surface, exhibiting some cracks. In contrast, the morphology of CAZ (Fig. 2b) and CAH (Fig. 2c) indicate that the activation processes caused modifications resulting in the development of a porous surface. The presence of more open pores in the CAZ sample were observed, while the CAH sample had more closed pores with more collapsed structure. The CAC, used as a comparison, presented a morphological structure (Fig. 2d) distinct from the CAH and CAZ, which is probably related to the precursor used in the preparation.
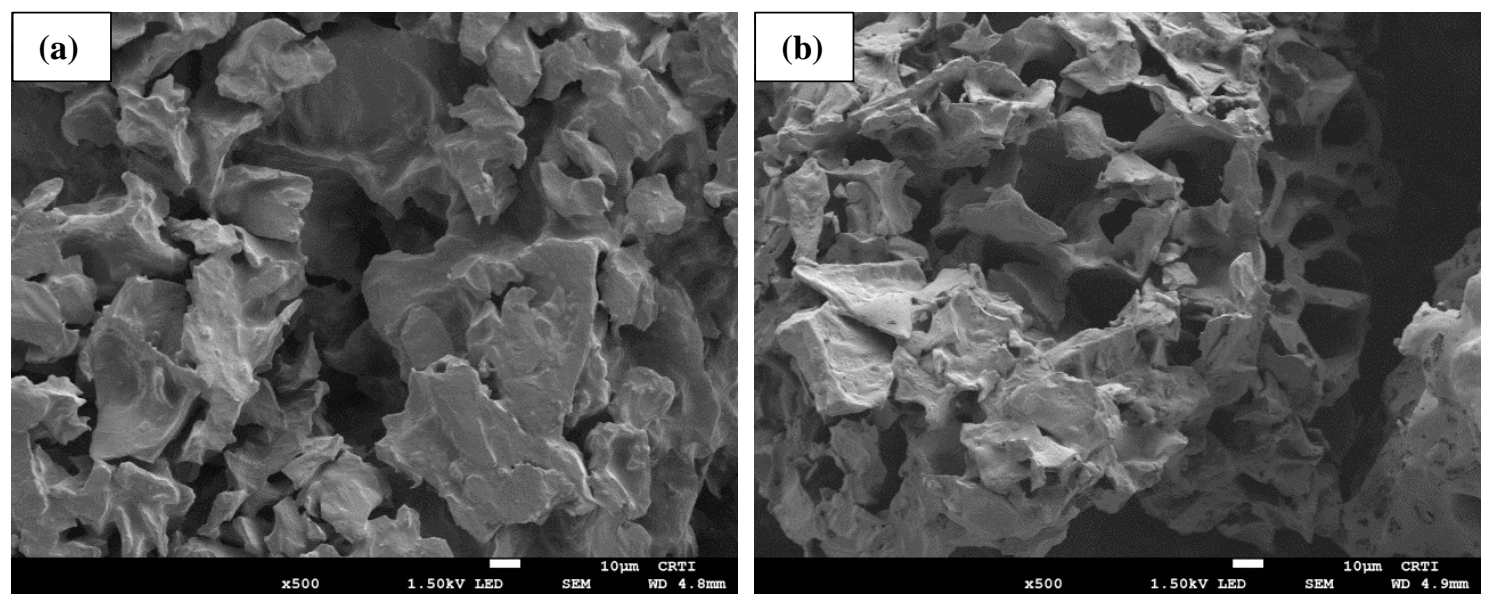

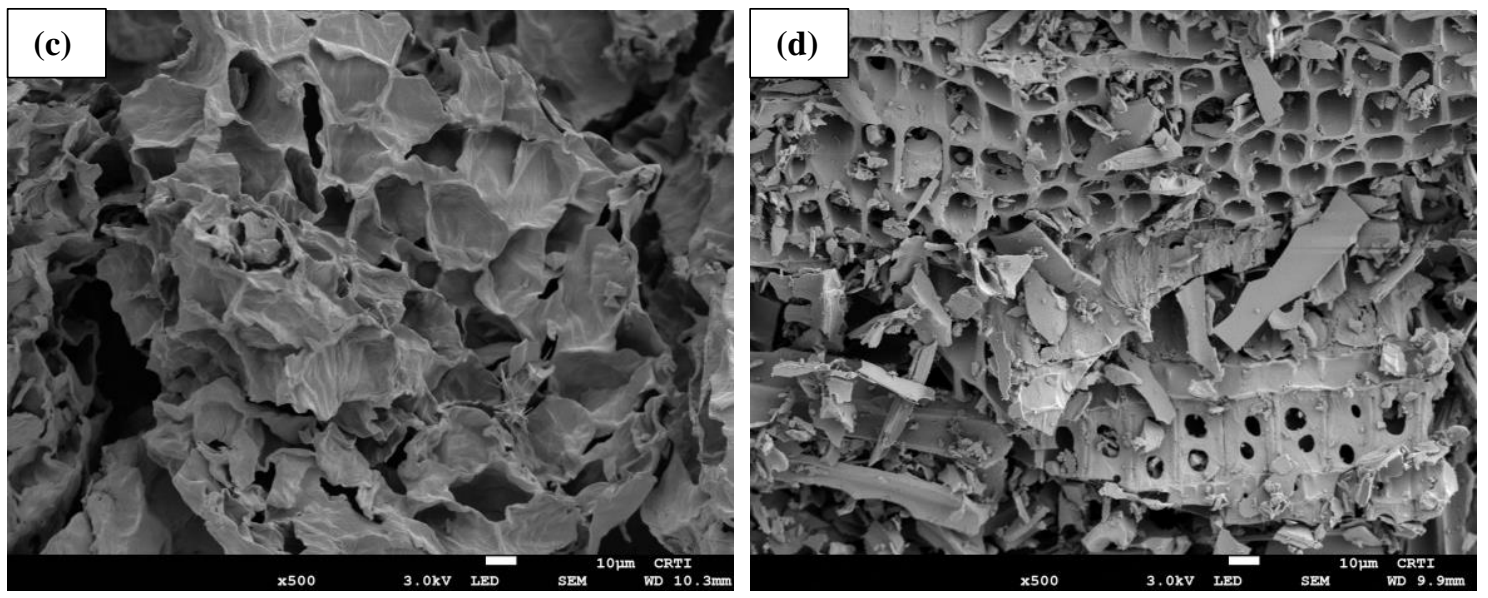

Fig. 2 Scanning electron microscopy images of raw material (a), CAZ (b), CAH (c) and CAC (d)

$X$-ray diffraction $(X R D)$

Fig. 3 shows the X-ray diffractograms of CAH and CAZ. For both materials, the typical formation of a structure of randomly arranged carbons occurs. It is possible to observe bands around $2 \theta=24.5^{\circ}$ and $2 \theta=$ $42^{\circ}$, corresponding to the diffraction of (002) and (100), respectively, which are graphite-like reflections (Hadoun et al. 2013; Suhas et al. 2017). The peak at around $24^{\circ}$ signifies an increasing regularity of crystalline structure, showing a tendency to result in a layer alignment. The micrograph structures are characteristic of activated carbons (Schettino Junior et al. 2007; Gao et al. 2015).

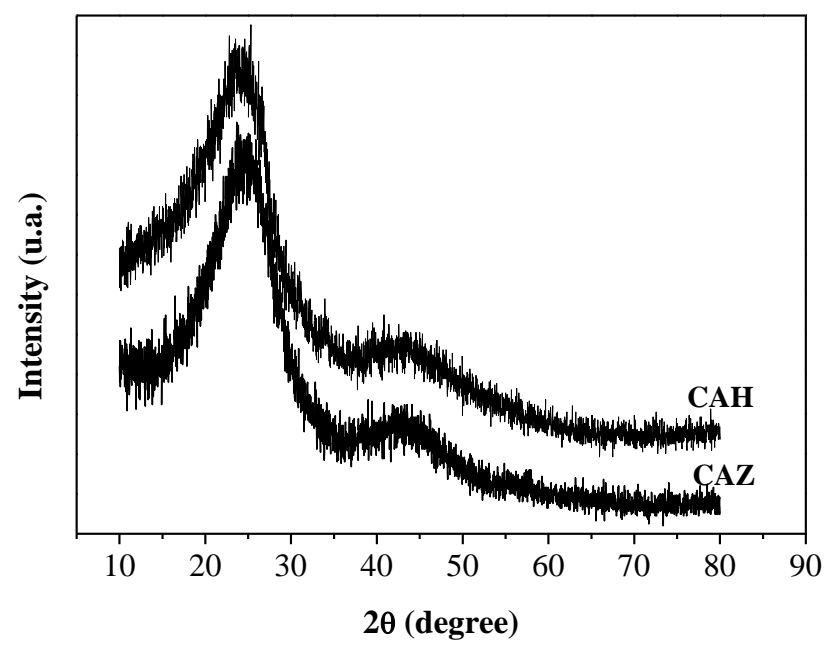

Fig. 3 XRD patterns of CAH and CAZ

Fourier transformer infrared spectroscopy (FTIR)

Fig. 4 shows the FTIR spectra of CAZ (Fig. 4a) and CAH (Fig. 4b). The bands around $3388 \mathrm{~cm}^{-1}$ and 3446 $\mathrm{cm}^{-1}$ are attributed to stretching vibrations at the hydroxyl groups $(\mathrm{O}-\mathrm{H})$, and the bands around $1568 \mathrm{~cm}^{-1}$ and $1566 \mathrm{~cm}^{-1}$ correspond to the $\mathrm{C}=\mathrm{C}$ bond of partially oxidized graphene rings (Silverstein et al. 2013). 

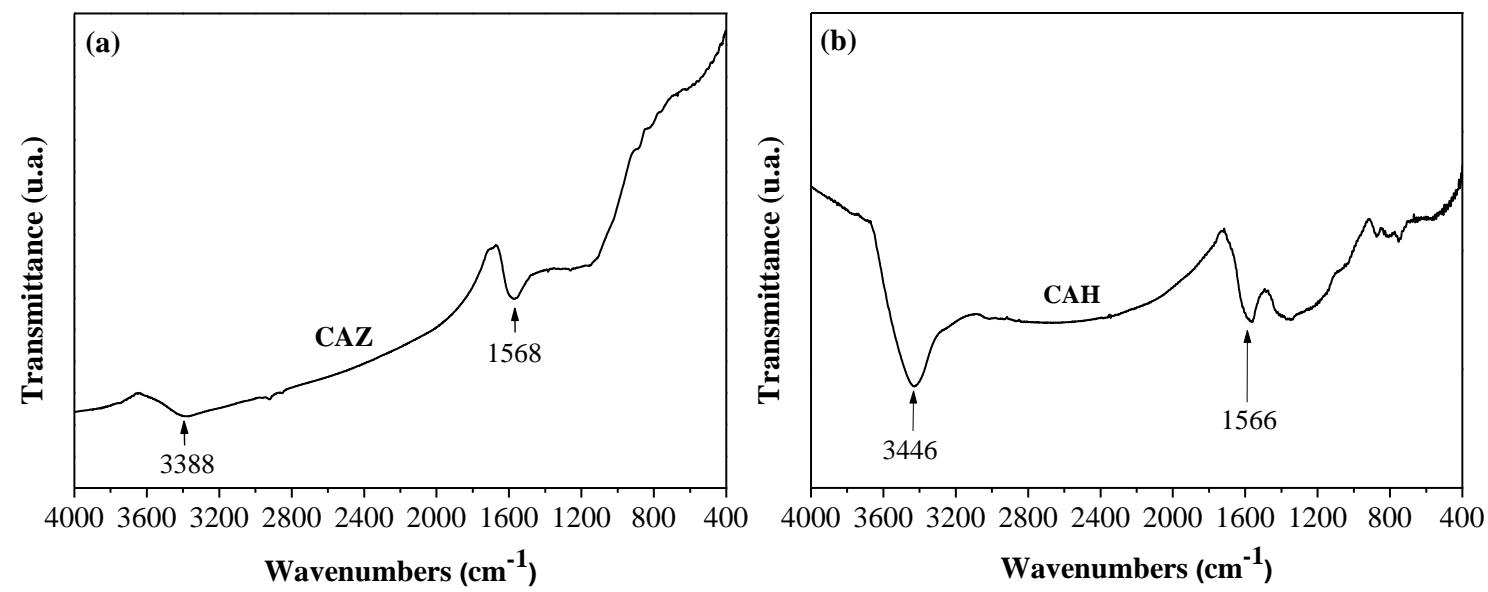

Fig. 4 FTIR spectra of CAZ (a) and CAH (b)

\section{BPA adsorption studies and Textural properties analysis}

Evaluation of the adsorption capacity of BPA

Preliminary adsorption tests using the CAZ, CAH, CAC and raw material were performed to discover their ability to adsorb BPA. The results are shown in Fig. 5.

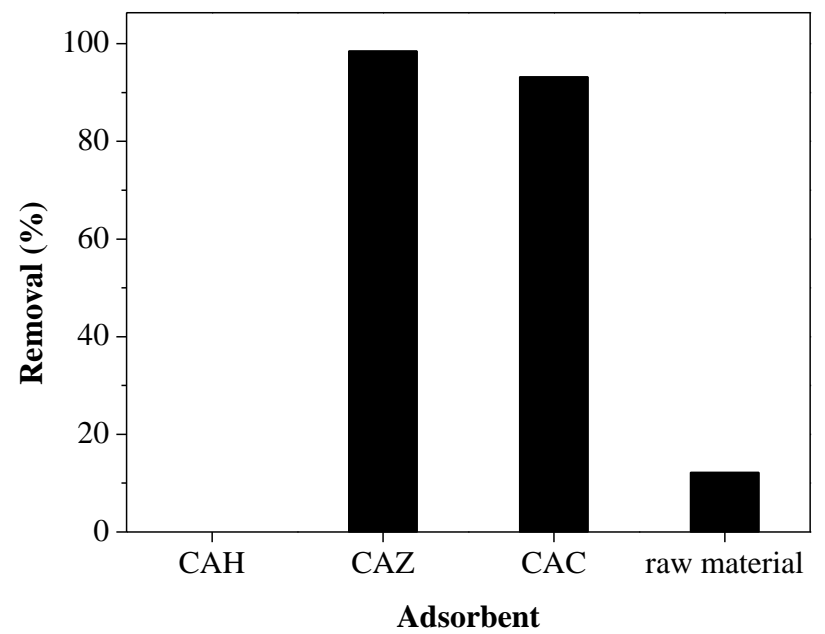

Fig. 5 Results of preliminary adsorption tests of the removal of BPA by CAZ, CAH, CAC and raw material

It can be observed that the CAH showed no adsorption of BPA, whereas the CAZ showed the highest adsorption of BPA with a removal of around $98 \%$. This was higher than the removal achieved with CAC that was around $93 \%$. The waste coffee grounds showed a BPA removal capacity of around 12\% without any activation. This low adsorption potential of BPA on untreated coffee grounds makes it unfeasible for the use of the waste coffee grounds as biosorbent in the removal of BPA. Therefore, it is necessary to change the morphology and functional groups of the waste coffee grounds, using for example activation processes, as performed in this study. 


\section{Textural properties analysis}

A preliminary analysis indicated a low surface area $\left(4.0 \mathrm{~m}^{2} / \mathrm{g}\right)$ for the CAH compared to the data from the literature, showing the surface area values higher than $400 \mathrm{~m}^{2} / \mathrm{g}$ (Tehrani et al. 2015; Rodiguez et al. 2018). The formation of the basic structure of the activated carbon occurs during the carbonization stage where the pore blockage due to the possible decomposition of the tar. In the activation process the tar compounds and the volatile material are removed and the pores are unlocked. If the raw material is directly subjected to activation, the porous structure formation is initiated, but it is not fully developed (Rodríguez-Reinoso and Molina-Sabio 1992). Thus, in addition to the absence of the carbonization step, the temperature of 500 ${ }^{\circ} \mathrm{C}$ used in the physical activation of raw material has most probably contributed to the low surface area formation $\left(4.0 \mathrm{~m}^{2} / \mathrm{g}\right)$.

Adsorption is influenced by several factors such as the nature of the adsorbent, the nature of the adsorbate and the conditions of the medium. The characteristics of the adsorbent that influence this process are: surface area, porosity, surface functional groups and point of zero charge (Bansal and Goyal 2005). Analyzing the $\mathrm{CAH}$, it is observed that its low surface area and poor porous structure are the cause for the absence of BPA adsorption capacity. Due to these reasons, the pore size distribution analysis was not performed for $\mathrm{CAH}$.

The CAZ presents close to Type I(b) isotherm (Fig. 6a), which is characteristic of microporous materials having relatively small external surfaces area and pores including also wider micropores and possibly narrow mesopores. This is also demonstrated by Fig. $6 \mathrm{~b}$ that shows presence of micropores with less than $2 \mathrm{~nm}$ diameter together with narrow mesopores with diameter 3-4 $\mathrm{nm}$. The isotherm shows also a Type $\mathrm{H} 4$ hysteresis, which is normally observed with Type IV isotherms and typical for carbonaceous materials with narrow pores in slit form and presence of micropores (Thommes et al. 2015). For the purpose of comparison, the analysis was also performed with the CAC.

The CAC presented close to Type IV(a) isotherm (Fig. 7a), which is characteristic of mesoporous materials, with a contribution of micropores. The CAC presented Type $\mathrm{H} 3$ hysteresis, where are observed aggregates of plate-like particles giving rise to slit-shaped pores (Thommes et al. 2015). Analyzing the pore distribution, CAC (Fig. 7b) has both meso- and micropores. The analysis shows the presence of pores with a diameter lower than $2 \mathrm{~nm}$, that correspond to the microporous structure and mesopores with diameter 3$4 \mathrm{~nm}$. In addition, CAC presented a higher volume of mesopores (30-40 $\mathrm{A}$ ) when compared with CAZ, which explains the larger hysteresis loop observed for the CAC (Everett 1971). 

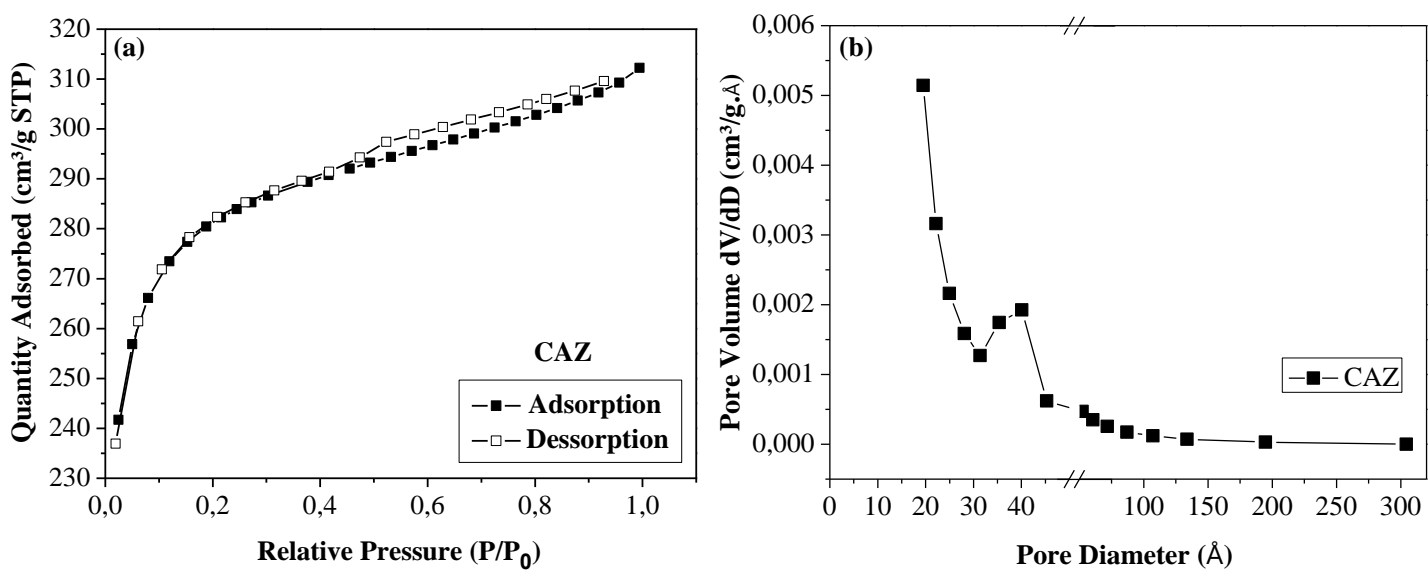

Fig. 6 Nitrogen adsorption-desorption (a). Pore size distributions for CAZ (b)
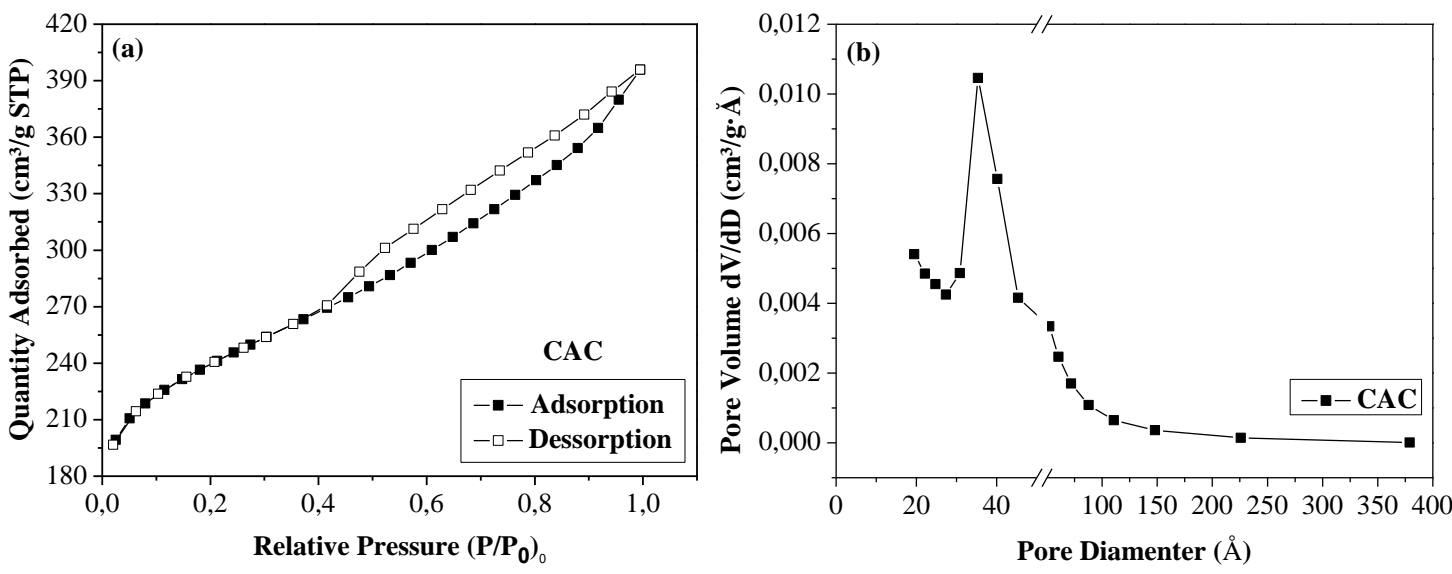

Fig. 7 Nitrogen adsorption-desorption (a). Pore size distributions for CAC (b)

The results presented in Table 2 show that the micropore volume of the CAZ corresponds to about $70 \%$ of the total pore volume, which characterizes $\mathrm{CAZ}$ as a microporous activated carbon, as discussed previously.

Table 2 Textural properties of the CAZ and CAC

\begin{tabular}{llllll}
\hline Adsorbent & $\begin{array}{l}\text { BET surface } \\
\operatorname{area}^{(1)}\left(\mathrm{m}^{2} / \mathrm{g}\right)\end{array}$ & $\begin{array}{l}\text { Total pore } \\
\text { volume }\end{array}$ & $\begin{array}{l}\text { Micropore } \\
\text { volume } \\
\left(\mathrm{cm}^{3} / \mathrm{g}\right)\end{array}$ & $\begin{array}{l}\text { Mesopore } \\
\left.\text { volume }^{(4)} \mathrm{g}\right)\end{array}$ & $\begin{array}{l}\text { Average pore } \\
\left.\mathrm{cm}^{3} / \mathrm{g}\right)\end{array}$ \\
\hline $\mathrm{CAZ}$ & 1039 & 0.481 & 0.339 & 0.142 & $<20$ \\
$\mathrm{CAC}$ & 869 & 0.598 & 0.212 & 0.386 & 47
\end{tabular}

(1) Calculated by the BET method / (2) calculated in $\mathrm{p} / \mathrm{p} 0=0,95 /$ (3) calculated by the method t-plot volume / (4) calculated by the difference between total volume of pores and micropores / (5) calculated by the BJH method.

The CAZ obtained a specific surface area of $1039 \mathrm{~m}^{2} / \mathrm{g}$ which is higher than the specific surface area of the CAC (about 16\%) and to some previous work reported in the literature, as presented in Table 3. 
Table 3 Comparison of surface areas of various activated carbons prepared from coffee grounds by chemical activation

\begin{tabular}{lllll}
\hline $\begin{array}{l}\text { Activating } \\
\text { agent }\end{array}$ & $\begin{array}{l}\text { BET surface } \\
\text { area }\left(\mathrm{m}^{2} / \mathrm{g}\right)\end{array}$ & $\begin{array}{l}\text { Activation } \\
\text { temperature }\end{array}$ & Heating rate & Reference \\
\hline $\mathrm{ZnCl}_{2}$ & 1039 & $500{ }^{\circ} \mathrm{C}$ & $10^{\circ} \mathrm{C} / \mathrm{min}$ & Presented study \\
$\mathrm{ZnCl}_{2}$ & 617 & $600{ }^{\circ} \mathrm{C}$ & $10^{\circ} \mathrm{C} / \mathrm{min}$ & (Khenniche and Aissani 2009) \\
$\mathrm{ZnCl}_{2}$ & 682 & $600{ }^{\circ} \mathrm{C}$ & $10^{\circ} \mathrm{C} / \mathrm{min}$ & (Boudrahem et al. 2011) \\
$\mathrm{K}_{2} \mathrm{CO}_{3}$ & 950 & $800{ }^{\circ} \mathrm{C}$ & $10^{\circ} \mathrm{C} / \mathrm{min}$ & (Castro et al. 2011) \\
$\mathrm{H}_{3} \mathrm{PO}_{4}$ & 910 & $600{ }^{\circ} \mathrm{C}$ & - & (Bouchenafa-Saïb et al. 2014) \\
$\mathrm{KOH}$ & 1348 & $800{ }^{\circ} \mathrm{C}$ & $5{ }^{\circ} \mathrm{C} / \mathrm{min}$ & (Laksaci et al. 2017) \\
\hline
\end{tabular}

The activated carbon produced in this study presented higher specific surface area compared to the other studies, with the exception of the adsorbent produced by Laksaci et al. (2017). Laksaci et al. (2017) used $\mathrm{KOH}$ in the activation of the coffee grounds and obtained a specific surface area of $1349 \mathrm{~m} / \mathrm{g}$. They also used $300{ }^{\circ} \mathrm{C}$ higher activation temperature than the one in this study and heating rate of $5{ }^{\circ} \mathrm{C} / \mathrm{min}$, which is half of what was used in $\mathrm{CAZ}$ production $\left(10^{\circ} \mathrm{C} / \mathrm{min}\right)$. These imply higher energy demand and inert gas costs in the production. The data presented in Table 3 show that large surface areas are not always related to the use of higher temperatures. It is possible to develop activated carbon with good textural and surface properties for adsorption by using less energy and inert gases.

Influence of $p H$ of the solution and point zero charge (pHPZC)

Fig. 8 shows the influence of the initial $\mathrm{pH}$ on the BPA removal efficiency $(\%)$ and the adsorbed amounts (qe) in the case of CAZ.

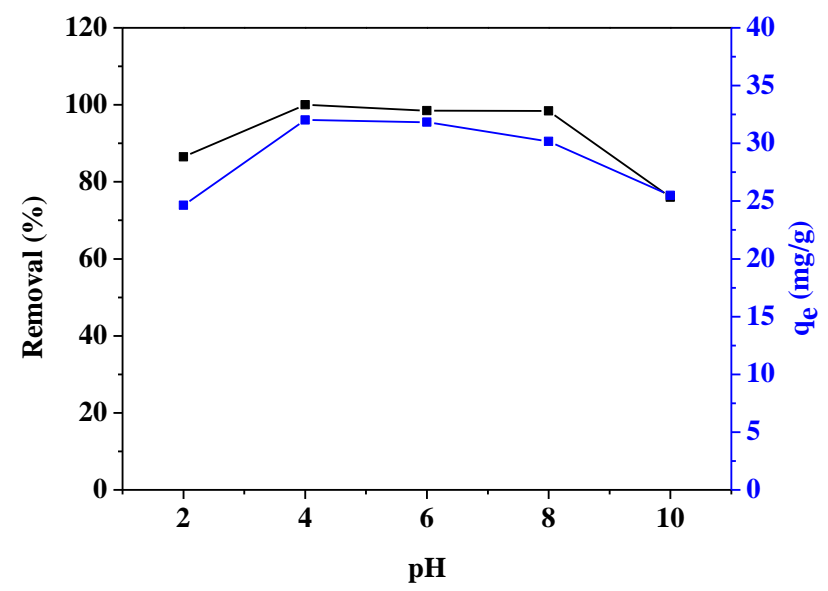

Fig. 8 Influence of the initial $\mathrm{pH}$ on the BPA adsorption demonstrated by the CAZ

The CAH sample did not adsorb BPA at any of the $\mathrm{pH}$ of the solution, which is related to the low specific surface area of $\mathrm{CAH}$, as discussed in 3.2.2. Textural properties analysis. Therefore, the point zero charge $\left(\mathrm{pH}_{\mathrm{PZC}}\right)$ was not determined for this adsorbent. As shown in Fig. 8, removal of BPA increased at $\mathrm{pH} 2$ to 4 and stays relatively constant from $\mathrm{pH} 4$ to 8 . However, the removal decreases when the $\mathrm{pH}$ is increased further from 8 to 10. In the $\mathrm{pH}$ range of 4 to 6 , the BPA removal was around $98 \%$ and the adsorption 
capacity was $32 \mathrm{mg} / \mathrm{g}$. At pH 2 and 10, the BPA removal was around 70\% and the adsorption capacity around $25 \mathrm{mg} / \mathrm{g}$.

Similar behavior was observed by Kamaraj et al. (2017) who studied the adsorption of BPA on activated carbon from the Ficus bengalensis bark, which showed relatively high and constant BPA removal at $\mathrm{pH}$ values of 6 to 8 compared the $\mathrm{pH}$ range from 3 to 5 and of 9 to 11 . The variations in BPA removal occur due to the adsorbent surface charge density and the charge of the bisphenol A species, which are dependent on the $\mathrm{pH}$ of the solution. For this reason, the $\mathrm{CAZ}$ pH $\mathrm{PZC}$ (Fig. 9) was determined.

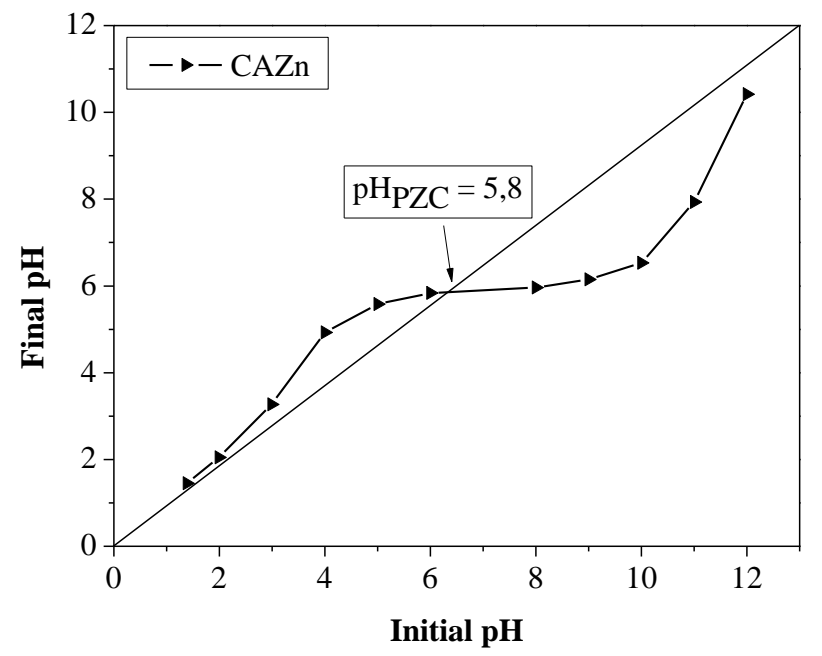

Fig. 9 Point zero charge $\left(\mathrm{pH}_{\mathrm{PZC}}\right)$ of $\mathrm{CAZ}$

Fig. 9 shows that the $\mathrm{pH}_{\mathrm{PZC}}$ of $\mathrm{CAZ}$ is equal to 5.8. Therefore, for $\mathrm{pH}$ values lower than 5.8, CAZ has positive charge on its surface and negative charge for $\mathrm{pH}$ values higher than $\mathrm{pH}$ PZC. When evaluating the adsorption, the behavior of BPA in different $\mathrm{pH}$ needs to be taken into account, because the pKa of BPA ranges from 9.6 to 10.2 (Yoon et al. 2003). For $\mathrm{pH}$ values in this range the chemical agent is deprotonated, losing $\mathrm{H}^{+}$ions to the medium, with the consequent formation of anions. In the acidic medium the BPA molecules are in form of neutral molecules.

At $\mathrm{pH} 10$ the $\mathrm{CAZ}$ has a negative surface charge because the $\mathrm{pH}$ of the medium is higher than the $\mathrm{pH}_{\mathrm{PZC}}$ of the CAZ. At this $\mathrm{pH}$ (range from 8 to 10) both BPA and CAZ are negatively charged, and BPA adsorption decreases (Fig. 8). The reduction occurs due to the electrostatic repulsion. At the $\mathrm{pH}$ values close to $\mathrm{pH}_{\mathrm{PZC}}$ the adsorbent surface charge density is zero, which increases the interaction between the CAZ surface and the dispersed BPA molecules, thus favoring their adsorption (Zbair et al. 2017).

Activated carbons are amphoteric materials in which surface charges depend on the $\mathrm{pH}$ of the solution. For values of $\mathrm{pH}<\mathrm{pH}_{\mathrm{PZC}}$ the surface of the activated carbon is positively charged, which favors the adsorption of anionic species. At $\mathrm{pH}>\mathrm{pH}$ PZC activated carbon has negative surface charges favoring the adsorption of cationic species (Belhachemi and Addoun 2011).

Fig. 9 shows that the $\mathrm{pH}_{\mathrm{PZC}}$ of the $\mathrm{CAZ}$ is 5.8 which justifies the reduction of the adsorption capacity of the $\mathrm{CAZ}$ at $\mathrm{pH} 10$, where both $\mathrm{CAZ}$ and BPA exhibit negative charges with an electrostatic repulsion. At $\mathrm{pH}$ values close to $\mathrm{pH}_{\mathrm{PZC}}$, the charge density of the adsorbent surface is zero, which increases the interaction between the CAZ surface and the dispersed BPA molecules. This behavior may justify the higher adsorption 
capacity of $\mathrm{CAZ}$ at $\mathrm{pH} 4$ and 6 . In addition, in the acid medium, the interaction between excess $\mathrm{H}^{+}$and $\mathrm{BPA}$ molecules takes place (Zbair et al. 2017).

Although a reduction in the adsorptive capacity of the $\mathrm{CAZ}$ sample was observed for values of $\mathrm{pH} 2.0$ and 10 , this reduction does not occur suddenly, indicating that the ion counter-charge is not a determining factor in the adsorption process. In this case, the adsorption may have been influenced by other mechanisms such as surface area and oxygen functional groups.

The amount adsorbed onto activated carbon can be inversely proportional to the oxygen content of the adsorbent (Pendleton et al. 2001). Thus, in extremely basic pH solutions, the solvent molecules can group around the oxygen sites, creating a region of polarized molecules. Thus, the interaction energy of the BPA molecule with the activated carbon surface is reduced (Pendleton et al. 2001; Pendleton et al. 2002). As shown in Table 1, the CAC presented oxygen 8.6 percentage points more than the CAZ, however it presented a surface area lower than the CAZ around 16\% (Table 2). Therefore, the data suggest that the high surface area of CAZ had greater influence on the adsorption, with a lower contribution of the oxygenated functional groups.

\section{Adsorption isotherm and kinetic models}

\section{Adsorption kinetics of $B P A$}

The adsorption kinetics for the three situations analyzed are relatively slow, because the equilibrium was established after approximately $720 \mathrm{~min}$, as shown in the Fig. 10.
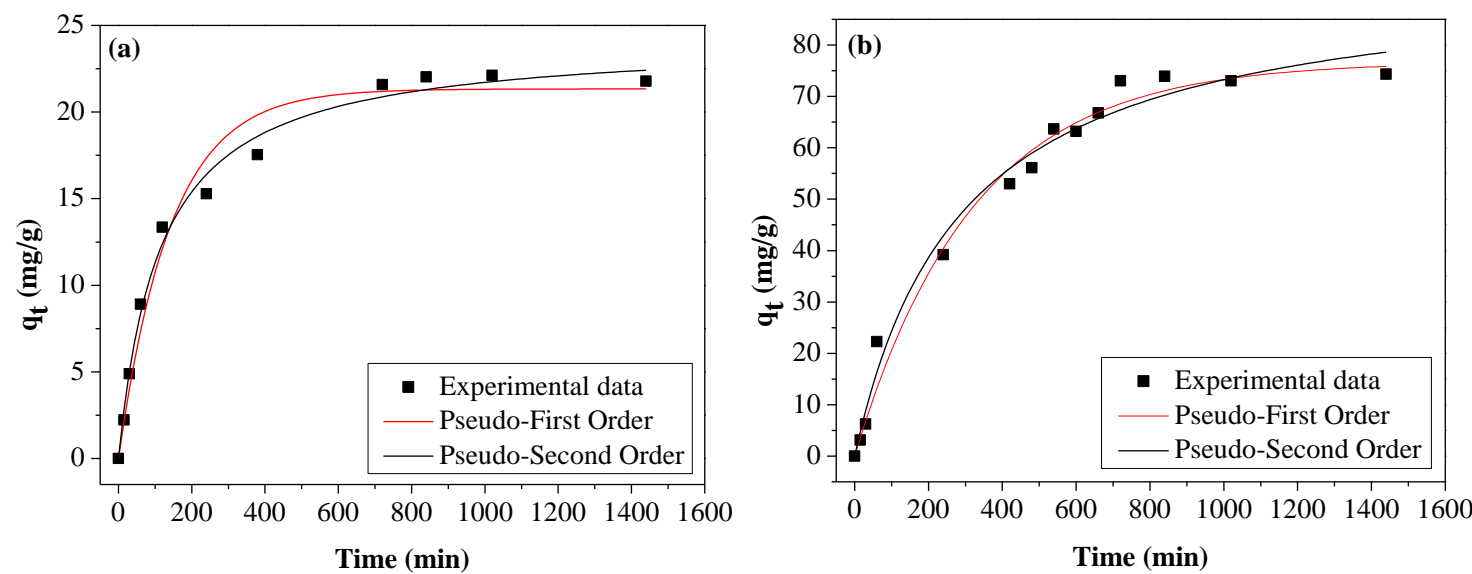


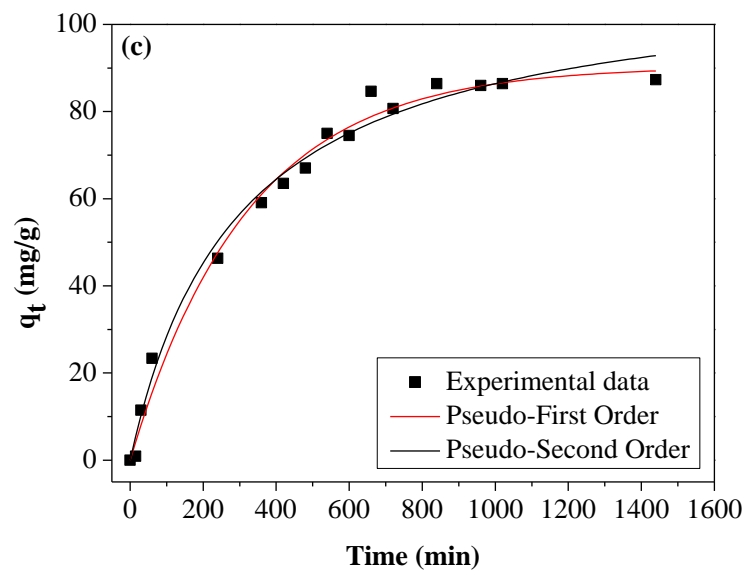

Fig. 10 BPA adsorption kinetics in CAZ at initial concentrations of (a) $5 \mathrm{mg} / \mathrm{L}$, (b) $20 \mathrm{mg} / \mathrm{L}$ and (c) $30 \mathrm{mg} / \mathrm{L}$ adjusted to the pseudo-first order and pseudo second order models

Table 4 shows the adsorption kinetic parameters obtained from the adjustment curves, as well as the amounts of BPA adsorbed by the CAZ (calculated experimentally) and the correlation coefficients $\left(\mathrm{R}^{2}\right)$ and Residual Sum of Squares (RSS).

Table 4 Kinetic parameters calculated from the adjustments of the pseudo-first-order and pseudo-second order models to the experimental data for CAZ

\begin{tabular}{|c|c|c|c|}
\hline $\begin{array}{l}\text { Initial concentration of BPA } \\
(\mathrm{mg} / \mathrm{L})\end{array}$ & $\mathrm{qe}_{\exp }(\mathrm{mg} / \mathrm{g})$ & Pseudo - First Order & Pseudo - Second Order \\
\hline \multirow{4}{*}{5} & \multirow{4}{*}{22.02} & $\mathrm{qe}_{\mathrm{cal}}=21.33$ & $\mathrm{qe}_{\mathrm{cal}}=24.18$ \\
\hline & & $\mathrm{k}_{1}=0.0069$ & $\mathrm{k}_{2}=0.00045$ \\
\hline & & $\mathrm{R}^{2}=0.975$ & $\mathrm{R}^{2}=0.991$ \\
\hline & & $\mathrm{RSS}=15.927$ & $\mathrm{RSS}=5.456$ \\
\hline \multirow{4}{*}{20} & \multirow{4}{*}{76.89} & $\mathrm{qe}_{\mathrm{cal}}=76.69$ & $\mathrm{qe}_{\mathrm{cal}}=78.63$ \\
\hline & & $\mathrm{k}_{1}=0.0031$ & $\mathrm{k}_{2}=0.00005$ \\
\hline & & $\mathrm{R}^{2}=0.985$ & $\mathrm{R}^{2}=0.985$ \\
\hline & & $\mathrm{RSS}=116.783$ & $\mathrm{RSS}=95.222$ \\
\hline \multirow{4}{*}{30} & \multirow{4}{*}{84.42} & $\mathrm{qe}_{\mathrm{cal}}=90.34$ & $\mathrm{qe}_{\mathrm{cal}}=93.78$ \\
\hline & & $\mathrm{k}_{1}=0.003$ & $\mathrm{k}_{2}=0.00003$ \\
\hline & & $\mathrm{R}^{2}=0.989$ & $\mathrm{R}^{2}=0.987$ \\
\hline & & $\mathrm{RSS}=157.208$ & $\mathrm{RSS}=179.598$ \\
\hline
\end{tabular}

$\mathrm{qe}=\mathrm{mg} / \mathrm{g} ; \mathrm{k} 1=1 / \mathrm{min} ; \mathrm{k} 2=\mathrm{g} / \mathrm{mg} \cdot \mathrm{min}$

The obtained data showed that the values of $\mathrm{qe}_{\mathrm{exp}}$ and $\mathrm{qe}_{\mathrm{cal}}$ are close for both kinetic models. Moreover, it was observed that, for the analyzed conditions, the $\mathrm{R}^{2}$ values in both models were also close. The RSS value for pseudo-second-order model is smaller than the value obtained from pseudo-first-order for the concentrations of $5 \mathrm{mg} / \mathrm{L}$ and $20 \mathrm{mg} / \mathrm{L}$ of BPA, which shows that the pseudo-second order model presented better fit to the experimental data. However, for $30 \mathrm{mg} / \mathrm{L}$ the RSS value for pseudo-second-order model is higher than the RSS value for the pseudo-first-order, but the difference is relatively small. Thus, the equation of order $n$ (Levenspiel 2000) was applied to the three situations of BPA concentrations studied (5 $\mathrm{mg} / \mathrm{L}, 20 \mathrm{mg} / \mathrm{L}$ and $30 \mathrm{mg} / \mathrm{L})$, which presented values of $\mathrm{n}=2.29\left(\mathrm{R}^{2}=0.921\right), \mathrm{n}=2.46\left(\mathrm{R}^{2}=0.995\right) \mathrm{n}=$ 
$2.60\left(R^{2}=0.99\right)$, respectively. As shown by the data, the $n$ values were close to 2 , so it was attributed that the adsorption kinetics in this study is better explained by the pseudo-second-order model. This result was also observed in some studies available in the literature related to the adsorption of BPA on activated carbons obtained from different raw materials (Koduru et al. 2016; Arampatzidou et al. 2017). The pseudosecond-order model describes chemical adsorption processes with electron exchange between adsorbate and adsorbent. BPA molecules are attracted to the active centers of the adsorbent with monolayer formation (Ho and McKay 1998).

\section{Adsorption isotherms of BPA}

The adsorption isotherms of BPA adjusted to the Langmuir and Freundlich models are shown in the Fig. 11.

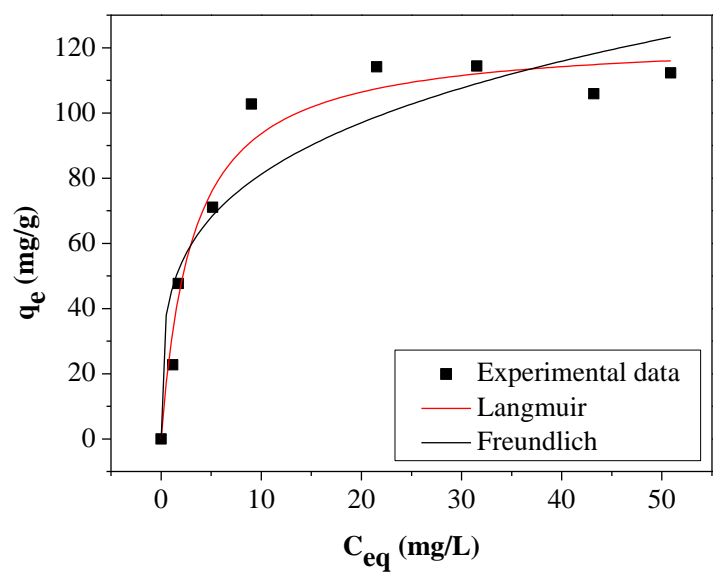

Fig. 11 BPA adsorption isotherm adjusted to the Langmuir and Freundlich models for CAZ

According to the Giles classification (Giles et al. 1960), the isotherm can be considered as type L, which presents an initial curvature facing downwards, indicating a reduction in the availability of the active sites with the increase of the adsorbent concentration. Furthermore, this isotherm also indicates the saturation of the surface on which the adsorbate has more affinity for the solvent than with the molecules already adsorbed. This fact can be related to the slow rate of adsorption observed during the kinetic experiments. The higher affinity of the adsorbate with the solvent makes it difficult to interact the adsorbate with the adsorbent, thus requiring a longer time to establish the equilibrium. Table 5 shows the calculated parameters for each equation as well as the values of the correlation coefficients $\left(\mathrm{R}^{2}\right)$ and Residual Sum of Squares (RSS). 
Table 5 Parameters of Langmuir and Freundlich models for BPA adsorption on CAZ

\begin{tabular}{lll}
\hline Models & Parameters & \\
\hline \multirow{3}{*}{ Langmuir } & $\mathrm{Q}_{\max }(\mathrm{mg} / \mathrm{g})$ & 123.2 \\
& $\mathrm{~K}_{\mathrm{L}}(\mathrm{L} / \mathrm{mg})$ & 0.316 \\
& $\mathrm{R}_{\mathrm{L}}$ & $0.35-0.04$ \\
& $\mathrm{R}^{2}$ & 0.968 \\
& $\mathrm{RSS}$ & 430.106 \\
& $\mathrm{~K}_{\mathrm{F}}(\mathrm{mg} / \mathrm{g})(\mathrm{mg} / \mathrm{L})^{-1 / n}$ & 44.97 \\
Freundlich & $\mathrm{n}$ & 3.89 \\
& $1 / \mathrm{n}$ & 0.257 \\
& $\mathrm{R}^{2}$ & 0.874 \\
& $\mathrm{RSS}$ & 1692.404 \\
\hline
\end{tabular}

Langmuir model is the most suitable for explain the BPA adsorption on CAZ data because this model has a $R^{2}$ value close to $1(0.968)$ compared to Freundlich model $\left(R^{2}=0.874\right)$. In addition, the RSS value was smaller for the Langmuir model (RSS $=430.106$ ), while the Freundlich model presented RSS $=1692.404$. In this aspect, according to the Langmuir model description, the CAZ presents monolayer adsorption in a localized way and without interaction between the adsorbed molecules. Moreover, the heat of adsorption is independent on the surface coverage, since the adsorbent has homogeneous surface energy. The $\mathrm{R}_{\mathrm{L}}$ value determined was in the range of $0<\mathrm{R}_{\mathrm{L}}<1$, which indicates that the adsorption process of BPA on CAZ was favorable. The Langmuir model also shows the parameter of maximum adsorption capacity $\left(\mathrm{q}_{\max }\right)$, which is $123.2 \mathrm{mg} / \mathrm{g}$. The best correlation between the experimental data and the Langmuir model was also reported by other studies in the literature. Asada et al. (2004) used commercial activated carbon in adsorption of BPA and obtained a $\mathrm{q}_{\max }$ of $56.5 \mathrm{mg} / \mathrm{g}$.

Wirasnita et al., 2014 produced an activated carbon from the palm shell, which showed a $\mathrm{q}_{\max }$ of 41.98 $\mathrm{mg} / \mathrm{g}$. Pamidimukkala and Soni (2018) used also activated carbon from palm shell for adsorption of BPA and obtained a $\mathrm{q}_{\max }$ of $45.45 \mathrm{mg} / \mathrm{g}$. It is visible that the activated carbon of coffee grounds (CAZ) produced in this study by chemical activation has a higher adsorption capacity of BPA when compared to the earlier studied materials.

\section{Conclusion}

The activated carbon $\mathrm{CAZ}$ produced from coffee grounds waste using $\mathrm{ZnCl}_{2}$ as an activating agent is an effective adsorbent for removal of BPA and should be tested for removal of other emerging pollutants from the water as well. The CAZ had a higher specific surface area $\left(1039 \mathrm{~m}^{2} / \mathrm{g}\right)$ than the CAH $\left(4.0 \mathrm{~m}^{2} / \mathrm{g}\right)$, which was prepared using water vapor in the activation process. In addition, the CAZ had a carbon content above 90\% and presented the adsorption isotherm that was mixture of Types I and IV. This is characteristic for the materials that represent both micro- and macroporosity.

The chemically activated CAZ showed high efficiency for BPA adsorption (98\%), which was superior to the commercial activated carbon CAC (93\%). The physically activated CAH showed no adsorption of BPA. The coffee grounds waste, used as a biosorbent, presented low efficiency in the removal of BPA (around $12 \%$ ) when compared to CAZ and CAC. The low performance of the coffee grounds waste (raw material) 
in the removal of BPA justifies the use of activation in modification its structure to reach more efficient adsorption material.

The adsorption tests of BPA indicated for the CAZ a maximum BPA adsorption capacity of $123.2 \mathrm{mg} / \mathrm{g}$, which is higher than the other adsorbents reported in the literature. The adsorption kinetic data of BPA on CAZ fitted well to the pseudo-second order kinetic model. The Langmuir isotherm model explained well the adsorption of BPA on CAZ.

For an economically viable process, it is necessary to carry out investigations as to the regeneration and reuse of the produced adsorbent. Such studies may indicate a sustainable process both in the production of activated carbon and in its application for the removal of contaminants in aqueous medium, an essential strategy to decontaminate drinking water.

\section{Acknowledgments}

The authors acknowledge the support of the Federal University of Goiás (UFG), the Federal Institute of Goiás (IFG) and the Foundation for Research (FAPEG) for the master's scholarship.

Conflict of Interest: The authors declare that they have no conflict of interest.

\section{References}

Arampatzidou AC, Voutsa D, Deliyanni EA, Matis KA (2017) Adsorption of endocrine disruptor bisphenol A by carbonaceous materials: Influence of their porosity and specific surface area. Desalin Water Treat 76:1-9. doi: 10.5004/dwt.2017.20706

Asada T, Oikawa K, Kawata K, et al (2004) Study of Removal Effect of Bisphenol A and \&beta;Estradiol by Porous Carbon. J Heal Sci 50:588-593. doi: 10.1248/jhs.50.588

Aznar JS (2011) Characterization of activated carbon produced from coffee residues by chemical and physical activation. Thesis, KTH Vetenskap Och Konst, Stockolm

Bansal CR, Goyal M (2005) Adsorption, fisrt. CRC Press, New York

Barrett E., Joyner L., Halenda P. (1951) The Determination of Pore Volume and Area Distributions in Porous Substances. I. Computations from Nitrogen Isotherms. J Am Chem Soc 73:378-380

Belhachemi M, Addoun F (2011) Comparative adsorption isotherms and modeling of methylene blue onto activated carbons. Appl Water Sci 1:111-117. doi: 10.1007/s13201-011-0014-1

Blanchard G, Maunaye M, Martin G (1984) Removal of heavy metals from waters by means of natural zeolites. Water Res 18:1501-1507. doi: 10.1016/0043-1354(84)90124-6

Bouchenafa-Saïb N, Mekarzia A, Bouzid B, et al (2014) Desalination and Water Treatment Removal of malathion from polluted water by adsorption onto chemically activated carbons produced from coffee grounds. Desalin Water Treat 52:4920-4927. doi: 10.1080/19443994.2013.808845

Boudrahem F, Soualah A, Aissani-Benissad F (2011) Pb ( II ) and Cd ( II ) Removal from Aqueous Solutions Using Activated Carbon Developed from Coffee Residue Activated with Phosphoric Acid and Zinc Chloride. J Chem Eng 56:1946-1955. doi: dx.doi.org/10.1021/je1009569

Brunauer S, Emmett PH, Teller E (1938) Adsorption of Gases in Multimolecular Layers. J Am Chem Soc 60:309-319. doi: 10.1021/ja01269a023

Castro CS, Abreu AL, Silva CLT, Guerreiro MC (2011) Phenol adsorption by activated carbon produced from spent coffee grounds. Water Sci Technol 64:2059-65. doi: 10.2166/wst.2011.786

Djilani C, Zaghdoudi R, Modarressi A, et al (2012) Elimination of organic micropollutants by adsorption 
on activated carbon prepared from agricultural waste. Chem Eng J j 189-190:203-212. doi: 10.1016/j.cej.2012.02.059

Essabir H, Raji M, Laaziz SA, et al (2018) Thermo-mechanical performances of polypropylene biocomposites based on untreated, treated and compatibilized spent coffee grounds. Compos Part B Eng 149:1-11. doi: 10.1016/j.compositesb.2018.05.020

Everett DH (1971) Manual of symbols and terminology for physicochemical quantities and units. Appendix II - Definitions, Terminology and Symbols in Colloid and Surface Chemistry, Part I. Int Union Pure Appl Chem

Freundlich H (1906) Über die Adsorption in Lösungen. Zeitschrift für Phys Chemie 38:385-471

Gao Y, Li L, Jin Y, et al (2015) Porous carbon made from rice husk as electrode material for electrochemical double layer capacitor. Appl Energy 153:41-47. doi:

10.1016/j.apenergy.2014.12.070

Giles CH, MacEwan TH, Nakhwa SN, Smith D (1960) Studies in adsorption. Part XI. A system of classification of solution adsorption isotherms, and its use in diagnosis of adsorption mechanisms and in measurement of specific surface areas of solids. J Chem Soc 846:3973-3993

Gwenzi W, Chaukura N, Noubactep C, Mukome FND (2017) Biochar-based water treatment systems as a potential low-cost and sustainable technology for clean water provision. J Environ Manage 197:732-749. doi: 10.1016/j.jenvman.2017.03.087

Hadoun H, Sadaoui Z, Souami N, et al (2013) Characterization of mesoporous carbon prepared from date stems by H3PO4 chemical activation. Appl Surf Sci 280:1-7. doi: 10.1016/j.apsusc.2013.04.054

Ho YS, McKay G (1998) A Comparison of Chemisorption Kinetic Models Applied to Pollutant Removal on Various Sorbents. Process Saf Environ Prot 76:332-340. doi: 10.1205/095758298529696

Kamaraj M, Satheesh K, Rajeshwari S (2017) Bioremediation and Sustainable Technologies for Cleaner Environment. Bioremediation Sustain Technol Clean Environ Environ Sci Eng 163-176. doi: 10.1007/978-3-319-48439-6

Khenniche L, Aissani F (2009) Characterization and utilization of activated carbons prepared from coffee residue for adsorptive removal of salicylic acid and phenol : Kinetic and isotherm study. Desalin Water Treat 11:192-203. doi: 10.5004/dwt.2009.801

Koduru RJ, Lingamdinne PL, Singh J, Choo K (2016) Effective removal of bisphenol A ( BPA ) from water using a goethite / activated carbon composite. Process Saf Environ Prot 103:87-96. doi: 10.1016/j.psep.2016.06.038

Lagergren S (1898) About the theory of so-called adsorption of soluble substances. K Sven Vetenskapsakademiens Handl 24:1-39

Laksaci H, Khelifi A, Trari M, Addoun A (2017) Synthesis and characterization of microporous activated carbon from coffee grounds using potassium hydroxides. J Clean Prod 147:254-262. doi: https://doi.org/10.1016/j.jclepro.2017.01.102

Langmuir I (1916) The constitution and fundamental properties of solids and liquids. Part I. Solids. J Am Chem Soc 38:2221-2295

Levenspiel O (2000) Engenharia das reações químicas, 3rd edn. Blucher, São Paulo

Marsh H, Rodriguez-reinoso F (2006) Activated Carbon. Elsevier

Moreira M, Aquino S, Coutrim M, et al (2011) Determination of endocrine - disrupting compounds in waters from Rio das Velhas , Brazil , by liquid chromatography / high resolution mass spectrometry (ES-LC-IT-TOF/MS). Environ Technol 32:1409-1417. doi: 10.1080/09593330.2010.537829

Nasseri S, Ebrahimi S, Abtahi M, Saeedi R (2018) Synthesis and characterization of polysulfone / graphene oxide nano- composite membranes for removal of bisphenol A from water. J Environ Manage 205:174-182. doi: 10.1016/j.jenvman.2017.09.074

Nowicki P (2016) Effect of heat treatment on the physicochemical properties of nitrogen-enriched activated carbons. J Therm Anal Calorim 125:1017-1024. doi: 10.1007/s10973-016-5254-8

Ozdemir I, Şahin M, Orhan R, Erdem M (2014) Preparation and characterization of activated carbon from grape stalk by zinc chloride activation. Fuel Process Technol 125:200-206. doi: 
10.1016/j.fuproc.2014.04.002

Pamidimukkala PS, Soni H (2018) Efficient removal of organic pollutants with activated carbon derived from palm shell: Spectroscopic characterisation and experimental optimisation. J Environ Chem Eng 6:3135-3149. doi: 10.1016/j.jece.2018.04.013

Park J, Regalbuto JR (1995) A Simple, Accurate Determination of Oxide PZC and the Strong Buffering Effect of Oxide Surfaces at Incipient Wetness. J Colloid Interface Sci 175:239-252

Pendleton P, Schumann R, Wong SH (2001) Microcystin-LR Adsorption by Activated Carbon. 8:1-8. doi: $10.1006 /$ jcis.2001.7616

Pendleton P, Wu SH, Badalyan A (2002) Activated Carbon Oxygen Content Influence on Water and Surfactant Adsorption. 240:235-240. doi: 10.1006/jcis.2001.8052

Prauchner MJ, Sapag K, Rodríguez-Reinoso F (2016) Tailoring biomass-based activated carbon for $\mathrm{CH} 4$ storage by combining chemical activation with $\mathrm{H} 3 \mathrm{PO} 4$ or $\mathrm{ZnCl} 2$ and physical activation with CO2. Carbon N Y 110:138-147. doi: 10.1016/j.carbon.2016.08.092

Rodiguez MH, Yperman J, Carleer R, et al (2018) Adsorption of Ni(II) on spent coffee and coffee husk based activated carbon. J Environ Chem Eng 6:1161-1170. doi: 10.1016/j.jece.2017.12.045

Rodríguez-Reinoso F, Molina-Sabio M (1992) Activated carbons from lignocellulosic materials by chemical and/or physical activation: an overview. Carbon N Y 30:1111-1118. doi: 10.1016/00086223(92)90143-K

Schettino Junior MA, Freitas JCC, Cunha AG, et al (2007) PREPARAÇÃO E CARACTERIZAÇÃo DE CARVÃO ATIVADO QUIMICAMENTE A PARTIR DA CASCA DE ARROZ. Quim Nova 30:1663-1668. doi: 10.1016/j.biortech.2006.08.001

Silverstein RM, Webster FX, David KJ (2013) Identificação espectrométrica de compostos orgânicos, 7rd edn. LTC, Rio de Janeiro, pp71-122

Singh YD, Mahanta P, Bora U (2017) Comprehensive characterization of lignocellulosic biomass through proximate, ultimate and compositional analysis for bioenergy production. Renew Energy 103:490500. doi: 10.1016/j.renene.2016.11.039

Sodré FF, Montagner CC, Locatelli MAF, Jardim WF (2007) Ocorrência de Interferentes Endócrinos e Produtos Farmacêuticos em Águas Superficiais da Região de Campinas (SP, Brasil). J Brazilian Soc Ecotoxicol 2:187-196

Suhas, Carrott PJM, Carrott MMLR, et al (2017) An innovative approach to develop microporous activated carbons in oxidising atmosphere. J Clean Prod 156:549-555. doi: 10.1016/j.jclepro.2017.04.078

Tehrani NF, Aznar JS, Kiros Y (2015) Coffee extract residue for production of ethanol and activated carbons. J Clean Prod 91:64-70. doi: 10.1016/j.jclepro.2014.12.031

Thommes M, Kaneko K, Neimark A V, et al (2015) Physisorption of gases, with special reference to the evaluation of surface area and pore size distribution (IUPAC Technical Report). Pure Appl Chem 87:1051-1069. doi: 10.1515/pac-2014-1117

WHO, FAO (2010) Toxicological and Health Aspects of Bisphenol A Report of Joint FAO / WHO Expert Meeting. Ottawa, Canada

Wirasnita R, Hadibarata T, Yusoff ARM, Yusop Z (2014) Removal of Bisphenol A from Aqueous Solution by Activated Carbon Derived from Oil Palm Empty Fruit Bunch. Water, Air, Soil Pollut 225:2148. doi: 10.1007/s11270-014-2148-x

Xia J, Ge Y, Di J, et al (2016) Journal of Colloid and Interface Science Ionic liquid-assisted strategy for bismuth-rich bismuth oxybromides nanosheets with superior visible light-driven photocatalytic removal of. 473:112-119. doi: 10.1016/j.jcis.2016.03.046

Yang H, Yan R, Hanping C, et al (2007) Characteristics of hemicellulose, cellulose and lignin pyrolysis. Fuel 86:1781-1788. doi: 10.1016/j.fuel.2006.12.013

Yoon Y, Westerhoff P, Snyder SA, Esparza M (2003) HPLC-fluorescence detection and adsorption of bisphenol A, 17 $\beta$-estradiol, and 17 $\alpha$-ethynyl estradiol on powdered activated carbon. Water Res 37:3530-3537. doi: 10.1016/S0043-1354(03)00239-2 
Zbair M, Ainassaari K, Drif A, et al (2017) Toward new benchmark adsorbents: preparation and characterization of activated carbon from argan nut shell for bisphenol A removal. Environ Sci Pollut Res 25:1869-1882. doi: 10.1007/s11356-017-0634-6 